\title{
Household-level risk factors for Aedes aegypti pupal density in Guayaquil, Ecuador
}

\author{
Thien-An Ha ${ }^{1 *}$, Tomás M. León ${ }^{1}$, Karina Lalangui ${ }^{2}$, Patricio Ponce ${ }^{2}$, John M. Marshall ${ }^{1}$ and Varsovia Cevallos ${ }^{2}$
}

\begin{abstract}
Background: Vector-borne diseases are a major cause of disease burden in Guayaquil, Ecuador, especially arboviruses spread by Aedes aegypti mosquitoes. Understanding which household characteristics and risk factors lead to higher Ae. aegypti densities and consequent disease risk can help inform and optimize vector control programs.

Methods: Cross-sectional entomological surveys were conducted in Guayaquil between 2013 and 2016, covering household demographics, municipal services, potential breeding containers, presence of Ae. aegypti larvae and pupae, and history of using mosquito control methods. A zero-truncated negative binomial regression model was fitted to data for estimating the household pupal index. An additional model assessed the factors of the most productive breeding sites across all of the households.

Results: Of surveyed households, 610 satisfied inclusion criteria. The final household-level model found that collection of large solid items (e.g., furniture and tires) and rainfall the week of and 2 weeks before collection were negatively correlated with average pupae per container, while bed canopy use, unemployment, container water volume, and the interaction between large solid collection and rainfall 2 weeks before the sampling event were positively correlated. Selection of these variables across other top candidate models with $\triangle \mathrm{AICc}<1$ was robust, with the strongest effects from large solid collection and bed canopy use. The final container-level model explaining the characteristics of breeding sites found that contaminated water is positively correlated with Ae. aegypti pupae counts while breeding sites composed of car parts, furniture, sewerage parts, vases, were all negatively correlated.
\end{abstract}

Conclusions: Having access to municipal services like bulky item pickup was effective at reducing mosquito proliferation in households. Association of bed canopy use with higher mosquito densities is unexpected, and may be a consequence of large local mosquito populations or due to limited use or effectiveness of other vector control methods. The impact of rainfall on mosquito density is multifaceted, as it may both create new habitat and "wash out" existing habitat. Providing services and social/technical interventions focused on monitoring and eliminating productive breeding sites is important for reducing aquatic-stage mosquito densities in households at risk for Ae. aegyptitransmitted diseases.

Keywords: Aedes aegypti, Mosquito, Household risk factors, Arbovirus, Collection services, Precipitation, Predictive modeling

${ }^{*}$ Correspondence: thienanha@berkeley.edu

1 School of Public Health, University of California, Berkeley, USA

Full list of author information is available at the end of the article

\section{Background}

Vector-borne febrile illnesses such as dengue, chikungunya, and Zika virus are of pressing public health concern in Latin America and the Caribbean [1]. The mosquito Aedes aegypti is the region's primary vector of these arboviruses, which co-circulate in populations in the tropics and subtropics $[1,2]$. The burden of these diseases weighs 
heavily on susceptible populations in low- and middleincome countries such as Ecuador [1].

Between 2010 and 2014, over 70,000 cases of dengue were reported in Ecuador, with the highest incidence clustered in urbanized coastal areas like the city of Guayaquil $[1,3]$. Dengue infection can be asymptomatic or present as a moderate febrile illness, with some symptoms advancing to hemorrhage, shock, and death [4]. Without an effective dengue vaccine, community and household-level vector control of Ae. aegypti remains the primary means of preventing and controlling dengue outbreaks [2]. In Ecuador, each household currently employs, on average, five different mosquito control methods, including sprays, aerosols, repellents, mosquito coils, screens, and bed nets [1].

Aedes aegypti population management is an ongoing public health challenge for countries with limited resources that must efficiently plan and utilize targeted control. Aedes aegypti is a mosquito species that primarily amplifies epidemics among urban populations [5]. The species is an effective vector for dengue because it is highly adapted to urban environments, where it lays eggs in artificial containers of water near human dwellings and preferentially feeds on humans [6]. Adult Ae. aegypti lay eggs in such habitats, and larvae develop in both natural water-retaining structures and in domestic water containers [7]. Examples of outdoor breeding sites for $\mathrm{Ae}$. aegypti include large tires, flower vases, and plastic gallon containers [8]. Understanding the local characteristics of Ae. aegypti habitats can be used to inform vector control efforts [9]. Previous studies done in Machala, Ecuador, found that local socio-ecological conditions such as proximity to abandoned properties, interruptions in the piped water supply, and a highly shaded patio were risk factors for Ae aegypti proliferation and the presence of dengue [2]. Further investigation into household factors, in conjunction with the evaluation of vector control efforts, is necessary to reduce and prevent dengue incidence by reducing Ae. aegypti habitat and population.

Our study describes potential household-level risk factors for Ae. aegypti pupal proliferation in the city of Guayaquil, Ecuador's largest and most populous city, its most important commercial port, and the historical epicenter of yellow fever and dengue in the country [1].

\section{Methods}

\section{Study site}

Guayaquil (2016 Instituto Nacional de Investigación en Salud Pública [INISP] projected population: 2,482,789) is located on the west bank of the Guayas River (Fig. 1), which flows into the Pacific Ocean. The urban core of Guayaquil is surrounded by low-income neighborhoods with limited basic services and high rates of migration.
Guayaquil has had the greatest number of dengue cases in Ecuador since 1988, with all four serotypes circulating since then. Seasonally, the highest incidence occurs in the rainy season because of favorable environmental conditions for transmission. The first 4 months of the year have abundant rain in this coastal region, with over 17 average days of rain totaling more than $200 \mathrm{~mm}$ each month; in the province of Guayas, the days are hot and humid, with average high temperatures between 29 and $32{ }^{\circ} \mathrm{C}$ and high humidity (US National Oceanic and Atmospheric Administration Integrated Surface Database [NOAA ISD] data).

\section{Household data collection}

Household cross-sectional surveys were conducted every month in Guayaquil from January 2013 to August 2016 to investigate factors correlated with mosquito pupal counts per container. Each month, one random subcircuit (an administrative unit covering $\sim 10,000$ inhabitants) was randomly selected in the Northern, Central, and Southern zones of Guayaquil, resulting in three sampling events (Fig. 1A). Guayaquil subcircuits were also classified into low, medium, and high socioeconomic status derived from three indicators: illiteracy, overcrowding, and unemployment (Fig. 1B). Each of these variables were averaged across the subcircuit, where illiteracy and unemployment were represented as percentages and overcrowding was the average number of people per household.

Households were defined as in-use residential units. Household addresses were obtained prior to the survey. Containers were defined as in-use breeding sites near or inside the household. Each container was examined for immature mosquito stages in the water, material, and type. Each house was visited only once in order to maximize the geographical area covered. Each visit assessed mosquito presence and conducted sampling in artificial containers of water. During each house visit, questions were asked to any household member over the age of 18 after verifying their residency. These questions focused on Ae. aegypti risk factors, including Ministry of Health vector control efforts and mosquito control practices which were used as candidate predictors in our model (Table 1, Additional file 1: Table S1).

\section{Meteorological data collection}

Precipitation data were obtained from the high-resolution satellite of the Climate Prediction Center $(\mathrm{CMORPH})$, with a temporal frequency every $0.5 \mathrm{~h}$ and a spatial resolution of $8 \times 8 \mathrm{~km}^{2}$. Precipitation data every $0.5 \mathrm{~h}$ were then aggregated by epidemiological week.

Precipitation measurements at week 0 , week 1 lag, and week 2 lag were included. Week 0 indicates the amount 


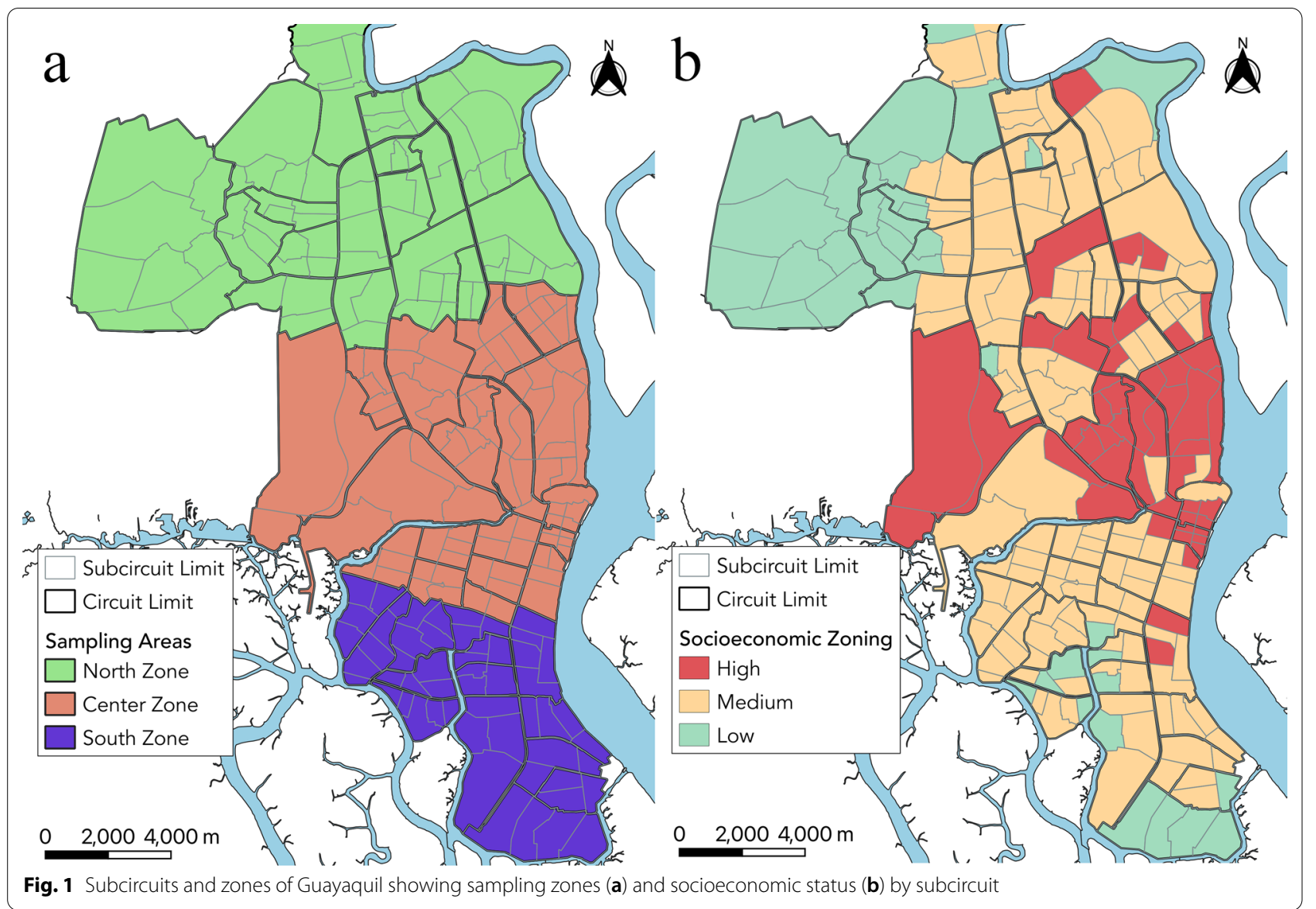

of rainfall the week that the sampling event occurred. The lag variables, week 1 lag and week 2 lag, indicate precipitation 1 week previous to the sampling event and precipitation 2 weeks previous to the sampling event, respectively. Only variables that were most relevant to mosquito ecology based on literature review and entomologist consultation were included for the models.

\section{Entomological sample collection}

Three field technicians conducted each sampling event, which took place across 250 households over a period of 5 days each time monthly during the study period (2013-2016). The criteria to select the sampling areas were based on areas with a high number of dengue cases reported by the Ecuadorian Health Ministry (MSP 2020). Sampling was done in all the neighborhoods (Northern, Central, and Southern zones) at the same time. Homes were chosen at random using the neighborhood main street as the transect. If there was no response in the selected home, a nearby home was selected. In each house, technicians searched for immature mosquitoes in containers both inside and outside of the household. Each container carrying immatures was recorded for its container type and material type. These live immatures were transported to an insectary in Quito, where the lab at INSPI recorded the numbers and stage of development. Immatures were reared until the adult stage for full species identification.

\section{Statistical analysis}

All analyses were performed in $\mathrm{R}$ version 3.5.3. We used zero-truncated negative binomial models to assess the appropriate household-level and container-level predictors of Ae. aegypti pupal population. Zero-truncated models were used because the data was only recorded for containers with immature mosquitoes present. Our outcome for the household-level statistical models was average pupal counts per container (APC), or pupal index, and was calculated as the total number of household pupae divided by the number of containers carrying these immature-stage mosquitoes. Our outcome for the secondary analysis on container-level data was the sum of the pupae in each artificial breeding site. We determined that outliers for each outcome were those beyond Q3 (75th percentile) +1.5* IQR (Q3-Q1) and omitted them [10]. 
Table 1 Summary statistics for habitat and vector control effort variables included in the analysis

\begin{tabular}{|c|c|c|}
\hline Variables of interest & $\begin{array}{l}\text { Number of } \\
\text { households }(n=610)\end{array}$ & Variable description \\
\hline Number of children & & Number of children ( $<18$ years) residing in the household \\
\hline 0 & $172(28 \%)$ & \\
\hline $1-3$ & $373(61 \%)$ & \\
\hline $4-7$ & $61(10 \%)$ & \\
\hline$>7$ & $4(1 \%)$ & \\
\hline Number of adults & & Number of adults ( $\geq 18$ years) residing in the household \\
\hline $0-3$ & $323(53 \%)$ & \\
\hline $4-7$ & $258(42 \%)$ & \\
\hline$>7$ & $29(5 \%)$ & \\
\hline Water interruption & & Whether or not the household experience a water service interruption in the last $24 \mathrm{~h}$ \\
\hline Yes & $153(25 \%)$ & \\
\hline No & $457(75 \%)$ & \\
\hline Trash service per week & & Number of times garbage collections occurs at the household per week \\
\hline $0-3$ & $529(87 \%)$ & \\
\hline $4-7$ & $81(13 \%)$ & \\
\hline Large solid collection & & Municipal service of collecting large furniture, tires, or other items \\
\hline Yes & $478(78 \%)$ & \\
\hline No & $132(22 \%)$ & \\
\hline Sewer connection & & Whether or not there is a sewer connection to the household's waste system \\
\hline Yes & $550(90 \%)$ & \\
\hline No & $60(10 \%)$ & \\
\hline Fumigation & & Spraying of deltamethrin, an insecticide applied inside the house every four months \\
\hline Yes & $190(31 \%)$ & \\
\hline No & $420(69 \%)$ & \\
\hline Abate & & $\begin{array}{l}\text { Also known as temephos, an organophosphate larvicide which is applied by } 20 \mathrm{~g} \text { of granular } \\
\text { product per } 189 \mathrm{~L}\end{array}$ \\
\hline Yes & $151(25 \%)$ & \\
\hline No & $459(75 \%)$ & \\
\hline Biolarvicide & & Bacillus thuringiensis used to target the larval stage of a mosquito \\
\hline Yes & $322(53 \%)$ & \\
\hline No & $288(47 \%)$ & \\
\hline Canopy use & & The usage of a canopy over a bed \\
\hline Yes & $287(47 \%)$ & \\
\hline No & $323(53 \%)$ & \\
\hline Protective mesh & & Mesh present around doors and windows \\
\hline Yes & $90(15 \%)$ & \\
\hline No & $520(85 \%)$ & \\
\hline Avg. water volume (L) & & Total water volume in all household breeding containers divided by the number of breeding sites \\
\hline $1-25$ & $435(71 \%)$ & \\
\hline $26-50$ & $21(4 \%)$ & \\
\hline$>50$ & 154 (25\%) & \\
\hline
\end{tabular}

We performed a Chi-square test for the Poisson model assumption that conditional variance equals conditional mean in our data set. We rejected the null hypothesis that the Poisson model best fits our data $(P<0.01)$ and fitted a negative binomial model with a dispersion parameter of 1.4103 and a standard error of 0.0881 . We fitted a full model using all variables for the household model (Additional file 1: Table S1) and the container model (Additional file 2: Table S2) and used the 'dredge' function ( $\mathrm{R}$ package MuMIn v1.43.17) to find all possible models through the best subset selection technique [11]. Best subset selection exhaustively searches all combinations 
of candidate variables and ranks models using specific selection criteria. In this study, we used the Akaike information criterion corrected for small sample sizes (AICc) to compare all the candidate models (Additional file 5: Fig S1 for the household-level models and Fig S2 for the container-level model). AICc has a penalty term for small sample sizes: as sample size increases, AIC is approximated, and therefore AICc is preferred over AIC [12]. Effect sizes were considered significant if $95 \%$ confidence intervals for corresponding explanatory variables did not overlap zero. We evaluated model performances using 100 simulations of tenfold cross-validation as our model evaluation method.

\section{Results}

In the surveys, 830 households of the total 990 households surveyed were found to have Ae. aegypti mosquito pupae. Of the 830 households, 220 had missing or erroneous location data (e.g., coordinates indicated a household was not in Guayaquil) and were omitted, yielding 610 households for our analysis. The mean pupal index for the subset of included households was 11.08, with a standard deviation of 10.26 , and a maximum pupal index of 42 .

About $47 \%$ of the 610 households used bed canopies as a method for preventing mosquito biting (Table 1). Approximately $25 \%$ of households had water service interruptions. Only $22 \%$ of households did not have large solid collection services. About $15 \%$ of households had protective mesh around their windows and doors.

\section{Influence of household-related factors on Ae. aegypti pupal abundance}

The model with the smallest (best) AICc value included the variables canopy use, large solid service, unemployment, water volume, precipitation at week 0 , precipitation at week $2 \mathrm{lag}$, and the interaction between large solid service and precipitation at week 2 lag (Table 2). The predictors with statistically significant associations were consistently selected into our top models $\Delta$ AICc $<1$ (Table 2). The explanatory variable estimates for the model with the smallest AICc value, our top model, indicated that canopy use, unemployment, average container water volume, and the interaction between large solid service and precipitation (with 2-week lag) all had a statistically significant positive relationship with Ae. aegypti pupal abundance and large solid service had a significant negative relationship with Ae. aegypti pupal abundance (Table 3).

The average prediction error over 100 simulations of tenfold cross-validation was 10 pupae off of the true value, where the mean pupal index was 11.08 . Figure 2 shows the distribution of pupal index measurements in households and prediction error mapped across Guayaquil (also see Additional file 7: Fig. S3 for corresponding heat maps and Additional file 8: Fig. S4 for relative error). Because of the tightly clustered sampling of some neighborhoods and the contribution of

Table 3 Explanatory variable estimates for the model with the smallest AICc value

\begin{tabular}{lcll}
\hline Variable & Log estimate & Estimate & $95 \% \mathrm{Cl}$ \\
\hline Intercept & 1.790 & 6.00 & $(3.68,9.79)$ \\
Canopy use & 0.240 & $1.271^{*}$ & $(1.06,1.52)$ \\
Large solid service & -0.280 & $0.756^{*}$ & $(0.610,0.932)$ \\
Unemployment & 0.0641 & $1.0662^{*}$ & $(1.02,1.114)$ \\
Water volume & 0.00166 & $1.0016^{*}$ & $(1.0003,1.003)$ \\
Precipitation & -0.00600 & 0.994 & $(0.986,1.0013)$ \\
Precipitation & -0.0103 & 0.990 & $(0.970,1.0118)$ \\
Large solid ser- $_{\text {vice }}^{*}$ precipitation & 0.0214 & $1.0216^{*}$ & $(1.00,1.043)$ \\
\hline
\end{tabular}

The response variable is the average pupae per container in a household ${ }^{*} P<0.05$

Table 2 Variables included in models with the smallest (best) AlCc values

\begin{tabular}{|c|c|c|c|c|}
\hline Model & $d f$ & LogLik & $\triangle \mathrm{AICC}$ & Error \\
\hline $\begin{array}{l}\text { Canopy use }+ \text { large solid service }+ \text { unemployment }+ \text { water volume }+ \text { precipitation }_{0}+\text { precipitation }_{2}+\text { large solid } \\
\text { service }^{*} \text { precipitation }_{2}\end{array}$ & 9 & -2075.162 & 0 & 10.08 \\
\hline $\begin{array}{l}\text { Canopy use + water interruption + large solid service + unemployment + water vol- } \\
\text { ume + precipitation }{ }_{0}+\text { precipitation }_{2}+\text { water interruption * }^{*} \text { precipitation } n_{0}+\text { large solid service }{ }^{*} \text { precipitation }{ }_{2}\end{array}$ & 11 & -2073.210 & 0.2374 & 10.12 \\
\hline 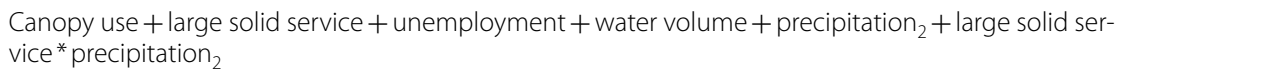 & 8 & -2076.444 & 0.5036 & 10.10 \\
\hline $\begin{array}{l}\text { Biolarvicide }+ \text { canopy use }+ \text { large solid service }+ \text { unemployment }+ \text { water vol- } \\
\text { ume }+ \text { precipitation }_{0}+\text { precipitation }_{2}+\text { large solid service }^{*} \text { precipitation }_{2}\end{array}$ & 10 & -2074.407 & 0.5566 & 10.09 \\
\hline 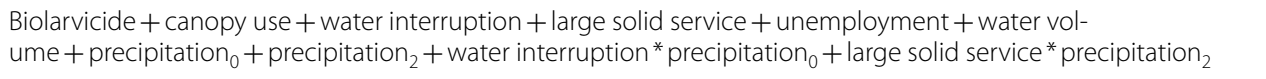 & 12 & -2072.431 & 0.7603 & 10.13 \\
\hline
\end{tabular}

Only models that lie within a $\triangle \mathrm{AICC}$ of 1 of the smallest AICc value are shown. The response variable was the total number of household Ae. aegypti pupae over the

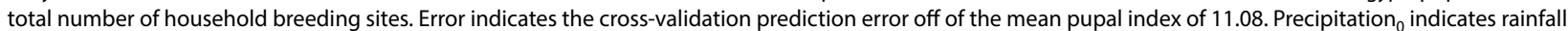
from the week of sampling and precipitation ${ }_{2}$ indicates rainfall with 2-week lag (i.e., 2 weeks before sampling) 


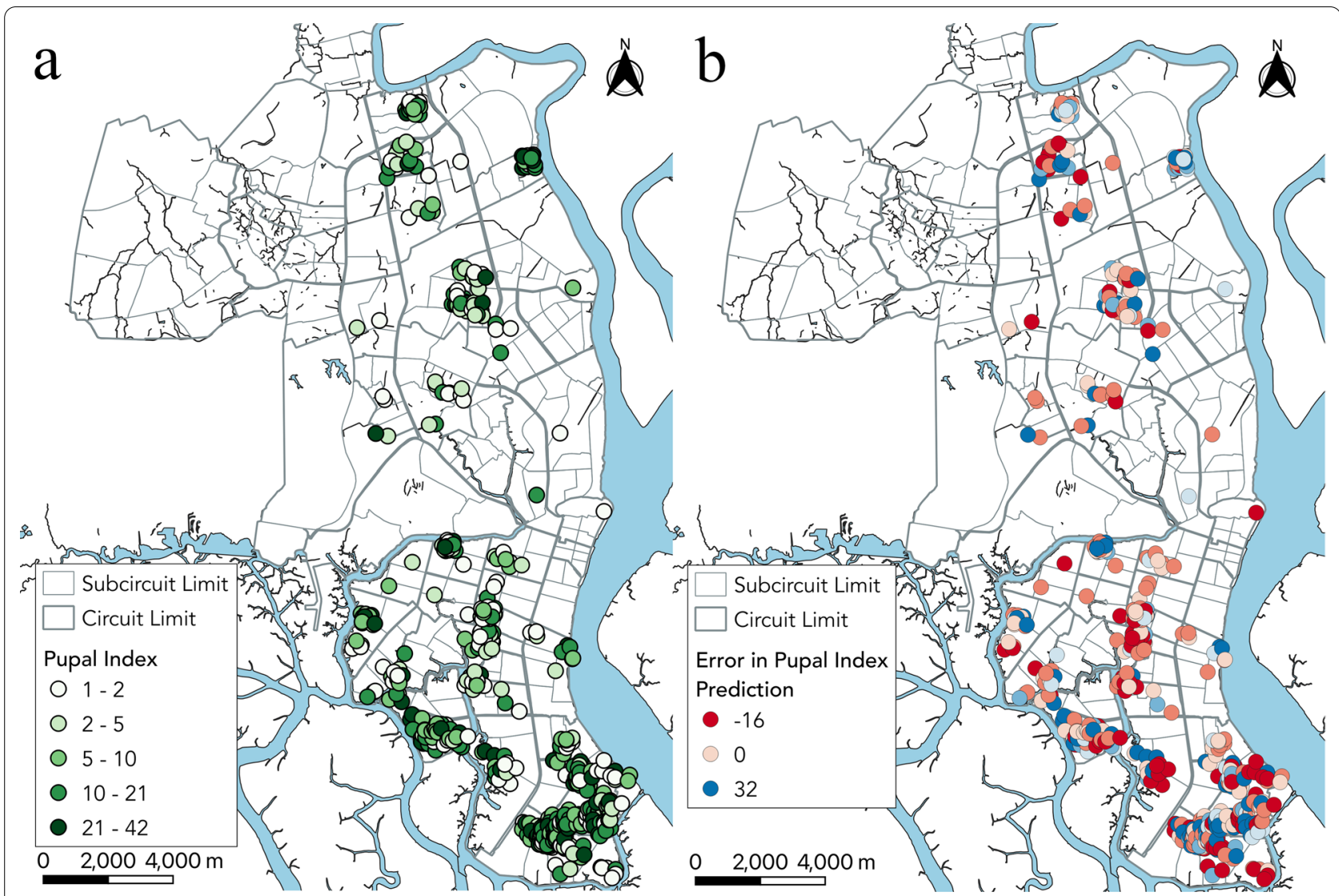

Fig. 2 Pupal index measurements (a) and prediction error map (b) based on the final model. Each dot indicates a household included in the final analysis. Error is the difference between the data and the model for each household's characteristics

local environmental effects, there was significant spatial autocorrelation (Moran's $I$ test, $P<0.01$ ). The socioeconomic variables (such as unemployment) captured some of these effects, but there were likely other unmeasured exposures contributing to the spatial pattern. An assessment of multicollinearity, excluding interaction terms, revealed that in our top model, none of the variables tested had variance inflation factor scores above 2 , indicating that there is little collinearity between predictors (Additional file 3: Table S3).

\section{Influence of container-related factors on Ae. aegypti pupal abundance}

We used data from 924 containers to conduct our analysis. The mean pupal sum for the included containers was 15.46, with a standard deviation of 21.63, and a maximum pupal count of 253. We observed that the top containerlevel models $(\triangle \mathrm{AICc}<1)$ consistently selected contaminated water, sewer parts, vases, ceramic material, glass material as appropriate predictors of pupal sum (Table 4, Additional file 4: Table S4).
The average prediction error over 100 simulations of tenfold cross validation for the container models was 21.54 pupae off of the true mean value of 15.46 pupae. The variables car parts, sewer, vase, ceramic material, glass material, metal material, and plastic material were all found to have a significant negative association with the outcome, pupal sum (Table 5). Contaminated water was the singular predictor found to have a significant positive association with pupal sum (Table 5).

\section{Discussion}

The burden of arboviruses transmitted by Ae. aegypti in Guayaquil has increased significantly since the 1980s, and targeted interventions are necessary to halt the spread of such diseases [3]. The findings of this study provide evidence that Ae. aegypti proliferation is influenced by specific household risk factors. The household models that performed best as determined by AICc contained the following variables: canopy use, large solid collection services, unemployment, water volume, water interruptions, biolarvicide, precipitation at week 0 , precipitation at week $2 \mathrm{lag}$, and the interactions precipitation at week 
Table 4 Variables included in container-level models with the smallest (best) AICc values

\begin{tabular}{|c|c|c|c|}
\hline Model & $d f$ & LogLik & $\triangle \mathrm{AlCc}$ \\
\hline $\begin{array}{l}\text { Car parts + contaminated water + furniture + ceramic material + glass material + metal material + plastic mate- } \\
\text { rial + sewer + vase }\end{array}$ & 11 & -3459.19 & 0 \\
\hline Car parts + contaminated water + ceramic material + glass material + metal material + plastic material + sewer + vase & 10 & -3460.23 & 0.03 \\
\hline $\begin{array}{l}\text { Bamboo + car parts + contaminated water + furniture + ceramic material + glass material + metal material + plastic mate- } \\
\text { rial + sewer + vase }\end{array}$ & 12 & -3458.20 & 0.08 \\
\hline $\begin{array}{l}\text { Bamboo + car parts + contaminated water + ceramic material + glass material + metal material + plastic mate- } \\
\text { rial + sewer + vase }\end{array}$ & 11 & -3459.24 & 0.11 \\
\hline $\begin{array}{l}\text { Bucket part + car parts + contaminated water + ceramic material + glass material + metal material + plastic mate- } \\
\text { rial + sewer + tub + vase }\end{array}$ & 12 & -3458.28 & 0.24 \\
\hline
\end{tabular}

Only models that lie within a $\triangle \mathrm{AICC}$ of 1 of the smallest AICc value are shown. The response variable was the total number of container-level Ae. aegypti pupae in each breeding site. Top five of all models with $\triangle \mathrm{AIC} C<1$ displayed

Table 5 Explanatory variable estimates for the container model with the smallest AICc value

\begin{tabular}{lccl}
\hline Variable & Log estimate & Estimate & $95 \% \mathrm{Cl}$ \\
\hline Intercept & 3.129 & 22.844 & $(17.74,29.98)$ \\
Car parts & -0.666 & $0.513^{*}$ & $(0.35,0.74)$ \\
Contaminated water & 0.247 & $1.280^{*}$ & $(1.10,1.49)$ \\
Furniture & -0.484 & 0.616 & $(0.35,1.21)$ \\
Ceramic material & -0.942 & $0.390^{*}$ & $(0.23,0.68)$ \\
Glass material & -0.900 & $0.407^{*}$ & $(0.23,0.74)$ \\
Metal material & -0.425 & $0.654^{*}$ & $(0.47,0.90)$ \\
Plastic material & -0.477 & $0.620^{*}$ & $(0.47,0.81)$ \\
Sewer & -0.617 & $0.540^{*}$ & $(0.31,1.02)$ \\
Vase & -0.414 & $0.661^{*}$ & $(0.46,0.97)$ \\
\hline
\end{tabular}

Response variable is pupal sum per container

${ }^{*} P<0.05$

0 * water interruption and large solid collection services * precipitation at a week 2 lag.

Canopy use was found to have a significant positive association with Ae. aegypti abundance, which is counterintuitive and may be attributed to other vector control practices being limited when bed canopies are in use. It is likely that those with higher mosquito populations inside the house are more prone to using bed canopies. The usage of these canopies may result in a false sense of security, or may be an indication of other unmeasured household risk factors that allow for high Ae. aegypti densities. The previously mentioned study from Machala, Ecuador, also cites an unclear relationship between dengue infections in a city near Guayaquil and bed canopy usage [2]. Furthermore, Ae. aegypti are daytime feeders, so these nets would only affect mosquito feeding if household members are napping during the day.

In our analysis, large solid collection services had a significant negative association with pupal abundance, which may be because there remain fewer untouched breeding sites available for Ae. aegypti. Regular bulky item pickup removes tires and other potential mosquito habitats where water could pool. This is corroborated by previous studies which have found that trash and flower pots are among the most common Ae. aegypti-positive containers [13]. These containers may be more regularly eliminated and maintained in higher socioeconomic areas through large solid collection services. In alignment with this finding, it was also found that unemployment had a significant positive relationship with pupal abundance. This corresponds with the comparison of the socioeconomic status map from Fig. 1 and the pupal index map from Fig. 2, where we find that there is a higher density of Ae. aegypti-positive households in lower socioeconomic areas. There is also a higher prediction error for these areas, as seen in Fig. 2 and Additional file 7: Fig. S3, suggesting that areas with higher unemployment need an emphasis on research to better understand the specific household risk factors attributed to Ae. aegypti pupal density (Additional file 6: Fig. S2).

Our study also found that average water volume had a significant positive relationship with pupal abundance. A 2012 study from the Tri Nguyen village in Vietnam found that containers where the water volume increased relative to the previous survey had a significantly higher count of Ae. aegypti pupae [14]. The study also found that the greatest increase in pupal abundance occurred after a rainfall event. This corresponds to our study's findings in which both precipitation during week 0 and increasing water volume resulted in higher APC. Heavy rainfall is known to flush out existing containers, which could explain the negative (not statistically significant) association between rainfall during the week of sampling and APC. A negative association (although again not statistically significant) between rainfall with a 2 -week lag and APC could conceivably result from the same flushing phenomenon, adjusting for the 8-12 days for Ae. aegypti eggs to develop into pupae $[15,16]$. The interaction between large solid collection services and precipitation 
2 weeks prior was significantly positively associated with Ae. aegypti pupal counts, which could be due to rainfall providing habitat for eggs to be laid which then develop into pupae 8-12 days later. The meaning of the interaction is somewhat unclear; however, wealthier neighborhoods had increased access to large solid collection services, so there was greater creation and destruction of mosquito habitat compared with poorer neighborhoods. Figure 2 shows that wealthier areas of Guayaquil have a lower number of high-density Ae. aegypti households. With fewer breeding habitats in wealthier neighborhoods, precipitation may have a larger and differential effect on pupal density, and therefore, any marginal effect may be picked up by the model.

This differentiation is further explained in the water storage practices and distribution of houses. In neighborhoods with higher employment rates and lower illiteracy, there are an increased number of natural areas where precipitation may collect, especially since houses are spread further apart. In less developed neighborhoods, there are different relationships with standing containers. During the rainy season, there are not as many water-holding containers because the water is constantly replenished by the rain. However, in the dry season, there are more standing containers because water is more scarce and needs to be stored for the households.

When the interaction term is included in the final model, precipitation at a week 2 lag has a negative correlation with the outcome. When the interaction term is not being controlled for, 14 days after a precipitation event correlates with higher pupal density. This suggests that there is a specific relationship between large solid collection services and precipitation at a week 2 lag on our outcome, pupal density. However, since large solid services may serve as a proxy for socioeconomic status, this may suggest a dynamic effect across socioeconomic statuses. These nuances are difficult to account for within the model context. For vector control efforts to be effective, it may require a more thorough understanding of the relationship between rainfall and socioeconomic factors that influence pupal density.

Aedes aegypti are highly adaptable mosquitoes that were historically found in forested areas using tree holes for breeding but have since adapted to breeding in tires, vases, and other objects found in proximity to human habitations [17]. Their resilience and adaptability pose difficulties when searching for effective control methods, especially for outdoor areas [17]. However, in light of our analyses, certain types and materials of containers may be more or less productive than others.

In our study, vase-type containers were found to be a significant predictor and were correlated with lower pupae counts. Glass material composition was selected as an appropriate explanatory predictor and was correlated with lower pupae counts as well. Vases, other glass-type containers, metal material, and ceramic material containers may have more variable water temperature that impedes Ae. aegypti development. Contaminated water was found to be a significant predictor correlated with higher pupae counts. The survey had field technicians qualitatively assess whether water was contaminated, so it was not quantifiably measured. Research suggests that Ae. aegypti prefer "clean" water, but this is a relative designation, as some nutrients in the water may support mosquito populations [7]. Contaminated water may have organic components within the container that promote algal growth and support mosquito proliferation. Water that is contaminated is likely to be untouched and stagnant, allowing Ae. aegypti to lay eggs and develop, as opposed to cleaner water, which may be flushed more often [7]. This finding is corroborated by previous studies that have noted that poor sanitation and water storing habits provide viable habitats for Ae. aegypti [3].

These results suggest that trash collection services targeting large solids and monitoring of containers that could serve as juvenile mosquito habitat contribute to suppressing Ae. aegypti pupal proliferation and consequent adult mosquito densities. These predictive models provide household factors of interest that could be included in future surveys to test hypotheses or assessed in rigorous causal models.

For the top household model, the mean error was high (10 pupae off of the true value) relative to the mean pupal index (11.0836). However, the standard deviation of the data is 10.263 indicating that the high error is due to the relatively high variance of the data, and the maximum pupal count is 253. Overdispersion and high variance are common in insect count data; therefore, these results remain valid [18].

There were months without sampling in each of the years for each of the three parts of Guayaquil; however, they did not share the same months missing in each area, so it was not possible to address this through a timeseries analysis to account for the repeated measurements on households. Predictive modeling has limitations. Best subset selection assesses $2^{p}$ models, where $p$ indicates the number of parameters, making the implementation of every interaction computationally infeasible when the number of parameters is large. Using previous literature, we assessed the most pertinent interactions and limited our model variable subset selection to $2^{21}$ models (Additional file 5: Fig. S1). This study could be improved with the inclusion of zero APC households to differentiate between containers and households that have zero mosquito pupae compared with those that have positive counts. Additionally, a longitudinal study, as opposed to 
the cross-sectional study design here, could track temporal dynamics in pupae populations. With a longitudinal study, a time-series analysis would be able to assess changing exposures to vector control methods and the environment and any subsequent changes in mosquito populations.

Future studies could correlate pupae counts with household demographics such as age and sex of inhabitants. Noting behavioral differences across these characteristics could also inform efforts for reducing mosquito proliferation and arbovirus spread. Additionally, further studies should compare our estimates of household factors in Guayaquil to those in more rural settings. Household risk factors such as water service interruption and temephos use may have a larger impact in more rural areas, where water interruptions may be more frequent. A similar study placed on an urban-to-rural gradient may help capture these effects. Additionally, dengue serological data could be incorporated to assess correlation between household risk factors and past exposure to dengue, which would be closer to the health endpoint and valuable for the public health sector. Random-effects modeling may further assess our covariates and outcomes with contextual understanding of variable distributions between and within households. Lastly, an understanding of competing dynamics between Ae. aegypti and other species of mosquitoes for habitat, breeding, and feeding would provide further context for targeted interventions in areas where multiple species coexist.

Furthermore, in this study, we used average pupae per container as our outcome measure. In this research field, similar studies have used other measures such as the Breteau index and house and container indices [1]. For this study, house and container indices were not used because the data set does not contain records of negative containers that did not contain Ae. aegypti larvae necessary to compute such indices. The Breteau index was not appropriate for this study because we explored individual household-level characteristics; however, this could be applied to a neighborhood-level study in the future.

\section{Conclusions}

The results of this study indicate that household factors influenced Ae. aegypti pupae proliferation from 2013 to 2016 in Guayaquil, Ecuador. The most notable household-level risk factors for pupae proliferation were the use of bed canopies, unemployment, and water volume in artificial containers, as well as precipitation with 2-week lag in conjunction with large solid collection. Providing services and social/technical interventions focused on monitoring and eliminating breeding sites may be important for reducing aquaticstage mosquito densities in households at risk for Ae. aegypti-transmitted diseases. The development of $A e$. aegypti prediction models contributes to public health efforts in Ecuador by providing information to optimize interventions for reducing mosquito densities and preventing dengue outbreaks.

\section{Abbreviations}

AIC: Akaike information criterion; AICc: Akaike information criterion corrected for small sample sizes; APC: Average pupal counts per container; IQR: Interquartile range; VIF: Variance inflation factors.

\section{Supplementary Information}

The online version contains supplementary material available at https://doi. org/10.1186/s13071-021-04913-0.

Additional file 1: Table S1. Full list of household candidate variables used to find the best model by AICC.

Additional file 2: Table S2. Full list of container-level candidate variables used to find the best model by AICC.

Additional file 3: Table S3. Variance inflation factors (VIF) that assess multicollinearity find that (outside of interaction terms) there are no VIF scores $>2$.

Additional file 4: Table S4. Full list of top candidate models for artificial breeding sites. Top models included have $\triangle \mathrm{AIC} C<1$

Additional file 5: Figure S1. Model selection table where the top axis are all the candidate variables for pupal index (Additional file 1: Table S1) and the $y$-axis represents the frequency the variables were selected in the top candidate models with $\triangle \mathrm{AICC}<2$ (31 models shown).

Additional file 6: Figure S2. Model selection table where the top axis are all the candidate variables for pupal sum in containers (Additional file 2: Table S2) and the $y$-axis represents the frequency the variables were selected in the top candidate models with $\triangle \mathrm{AIC} C<1$ ( 23 models total shown).

Additional file 7: Figure S3. Pupal index measurements (a) and prediction error heat maps (b) based on the final model. Weighted by value with a bandwidth of $1 \mathrm{~km}$. Error is the difference between the data and the model for each household's characteristics.

Additional file 8: Figure S4. Relative error map for pupal index prediction based on the final model. Each dot indicates the relative prediction error of that household, i.e., the difference between data and model for each household's characteristics divided by the data.

\section{Acknowledgements}

We thank Dr. Hsiang-Yu Yuan for helpful comments on the statistical aspects of the manuscript.

\section{Authors' contributions}

TH developed the hypothesis, analyzed and interpreted the entomological data, and authored most of the manuscript. TML assisted in the analysis and conception of the research idea, created the geographical figures, and was a main contributor in writing the manuscript. KL performed the geographical analyses to utilize for the geospatial figures. PP and VC guided the main data collection for this project and assisted in the conception of research idea as well as provided guidance on interpretation of the results for the paper. JM provided statistical guidance and was also a contributor in writing the manuscript. All authors read and approved the final manuscript.

\section{Funding}

The data collection for this work was supported by the Secretaria de Educación Superior, Ciencia, Tecnología e Innovación (SENESCYT), Proyecto PIC12-INHMT-002 (Grant PIC-12-INH-002). The analysis and processing portion of this research was supported by a 2019 Seed Fund award from Tecnológico de 
Monterrey and CITRIS and the Banatao Institute at the University of California and the Center for Global Public Health (CGPH) at University of California, Berkeley.

\section{Availability of data and materials}

The data sets generated and analyzed during the current study are not publicly available as they are the property of the Centro de Investigación en Vectores Artrópodos, Instituto Nacional de Investigación en Salud Pública "Dr. Leopoldo Izquieta Pérez", Quito, Ecuador. Data are however available from the corresponding author on reasonable request.

\section{Declarations}

\section{Ethics approval and consent to participate}

This research is not subject to IRB approval since it involves the secondary use of de-identified existing data.

\section{Consent for publication}

Not applicable.

\section{Competing interests}

The authors declare that they have no competing interests.

\section{Author details}

${ }^{1}$ School of Public Health, University of California, Berkeley, USA. ${ }^{2}$ Centro de Investigación en Vectores Artrópodos, Instituto Nacional de Investigación en Salud Pública "Dr. Leopoldo Izquieta Pérez", Quito, Ecuador.

Received: 30 November 2020 Accepted: 2 August 2021

Published online: 07 September 2021

\section{References}

1. Heydari N, Larsen DA, Neira M, Beltrán Ayala E, Fernandez P, Adrian J, et al. Household dengue prevention interventions, expenditures, and barriers to Aedes aegypti control in Machala, Ecuador. Int J Environ Res Public Health. 2017;14:196.

2. Kenneson A, Beltrán-Ayala E, Borbor-Cordova MJ, Polhemus ME, Ryan SJ, Endy TP, et al. Social-ecological factors and preventive actions decrease the risk of dengue infection at the household-level: results from a prospective dengue surveillance study in Machala, Ecuador. PLoS Negl Trop Dis. 2017;11:e0004621.

3. Lippi CA, Stewart-lbarra AM, Muñoz ÁG, Borbor-Cordova MJ, Mejía R, Rivero K, et al. The social and spatial ecology of dengue presence and burden during an outbreak in Guayaquil, Ecuador, 2012. Int J Environ Res Public Health. 2018;15:827.

4. Stewart-lbarra AM, Muñoz ÁG, Ryan SJ, Ayala EB, Borbor-Cordova MJ, Finkelstein $J$, et al. Spatiotemporal clustering, climate periodicity, and social-ecological risk factors for dengue during an outbreak in Machala, Ecuador, in 2010. BMC Infect Dis. 2014;14:610.
5. Zahouli JBZ, Utzinger J, Adja MA, Müller P, Malone D, Tano Y, et al. Oviposition ecology and species composition of Aedes spp. and Aedes aegypti dynamics in variously urbanized settings in arbovirus foci in southeastern Côte d'Ivoire. Parasites Vectors. 2016;9:523.

6. Ryan SJ, Mundis SJ, Aguirre A, Lippi CA, Beltrán E, Heras F, et al. Seasonal and geographic variation in insecticide resistance in Aedes aegypti in southern Ecuador. PLoS Negl Trop Dis. 2019;13:e0007448.

7. Paul KK, Dhar-Chowdhury P, Haque CE, Al-Amin HM, Goswami DR, Kafi $M A H$, et al. Risk factors for the presence of dengue vector mosquitoes, and determinants of their prevalence and larval site selection in Dhaka, Bangladesh. PLoS ONE. 2018;13:e0199457.

8. de Abreu FVS, Morais MM, Ribeiro SP, Eiras ÁE. Influence of breeding site availability on the oviposition behaviour of Aedes aegypti. Mem Inst Oswaldo Cruz. 2015;110:669-76.

9. Lin C-H, Schiøler KL, Ekstrøm CT, Konradsen F. Location, seasonal, and functional characteristics of water holding containers with juvenile and pupal Aedes aegypti in Southern Taiwan: a cross-sectional study using hurdle model analyses. PLoS Negl Trop Dis. 2018;12:e0006882.

10. Zhang $Y, Y e Z$, Lord D. Estimating dispersion parameter of negative binomial distribution for analysis of crash data. Transport Res Rec J Transport Res Board. 2007;2019:15-21.

11. Hastie T, Tibshirani R, Friedman J. The elements of statistical learning: data mining, inference, and prediction. Berlin: Springer Science \& Business Media; 2013.

12. Burnham KP, Anderson DR. Model selection and inference. New York: Springer; 1998.

13. Walker KR, Williamson D, Carrière Y, Reyes-Castro PA, Haenchen S, Hayden $\mathrm{MH}$, et al. Socioeconomic and human behavioral factors associated with Aedes aegypti (Diptera: Culicidae) immature habitat in Tucson. AZ J Med Entomol. 2018;55:955-63.

14. Jeffery JAL, Clements ACA, Nguyen YT, Nguyen LH, Tran SH, Le NT, et al. Water level flux in household containers in Vietnam-a key determinant of Aedes aegypti population dynamics. PLoS ONE. 2012;7:e39067.

15. Eisen L, Monaghan AJ, Lozano-Fuentes S, Steinhoff DF, Hayden MH, Bieringer PE. The impact of temperature on the bionomics of Aedes (Stegomyia) aegypti, with special reference to the cool geographic range margins. J Med Entomol. 2014;51:496-516.

16. Tun-Lin W, Burkot TR, Kay BH. Effects of temperature and larval diet on development rates and survival of the dengue vector Aedes aegypti in north Queensland, Australia. Med Vet Entomol. 2000;14:31-7.

17. Weaver SC, Reisen WK. Present and future arboviral threats. Antivir Res. 2010;85:328-45.

18. Sileshi G. Selecting the right statistical model for analysis of insect count data by using information theoretic measures. Bull Entomol Res. 2006;96:479-88.

\section{Publisher's Note}

Springer Nature remains neutral with regard to jurisdictional claims in published maps and institutional affiliations.
Ready to submit your research? Choose BMC and benefit from:

- fast, convenient online submission

- thorough peer review by experienced researchers in your field

- rapid publication on acceptance

- support for research data, including large and complex data types

- gold Open Access which fosters wider collaboration and increased citations

- maximum visibility for your research: over $100 \mathrm{M}$ website views per year

At BMC, research is always in progress.

Learn more biomedcentral.com/submissions 